\title{
The Relationship between Self-regulation, Self-efficacy, Test Anxiety and Motivation
}

\author{
Shakirat Abimbola Adesola and Yongmin Li
}

\begin{abstract}
The objective of this research was to investigate the relationship between self-efficacy, self-regulation, test anxiety and motivation as well as the relationship between test anxiety and academic performance. Twenty-four students of Computer Science in year two of their studies were examined in this study. Self-efficacy was found to be highly correlated with cognitive strategy use and self-regulation indicating that students who report high in self-regulation also applied cognitive strategy and self-efficacy in achieving their goals. The results also revealed that students that report high in self-regulation are more likely to report high in cognitive strategy use. Furthermore, the result of the study revealed that there is high correlation between test anxiety and academic outcomes.
\end{abstract}

Index Terms - Self-regulation, self-efficacy, test anxiety and motivation.

\section{INTRODUCTION}

Academic outcomes are important to both students and teachers determining the success rate of learning. It is therefore essential to identify the factors which affect academic outcomes such as the emotions students experience while in class or studying or during examinations. Achievement emotions are defined as emotions that arise in relation to achievement activities (for example, learning behaviour, effort investment, or task persistence) or subsequent outcomes (for example, evaluations according to quality standards) [1]. The main emotions associated with academic performances are Enjoyment, Anger, Boredom, Anxiety, Hopelessness, and Pride. However, anxiety seems to be the most studied among the academic performance emotions.

\section{Procedure FOR PAPER SUBMISSION}

This might be since many researchers consider test anxiety to be a multidimensional concept comparing of cognitive (worrying about one's own performance and consequence of failure), bodily-affective (for example, fast heartbeat associated with intense arousal), and behaviour manifestations (for example, task-irrelevant behaviour like avoidance) ([2]-[4]). Self-efficacy is determined by confidence beliefs of the student's approach to demands and

Manuscript received April 22, 2018; revised May 1, 2018.

Shakirat Abimbola Adesola is with the Department of Computer Science, Brunel University London, United Kingdom. She is on leave from Federal College of Education (Special), Oyo, Nigeria (e-mail: Shakirat.Adesola@brunel.ac.uk).

Yongmin $\mathrm{Li}$ is with the Department of Computer Science, Brunel University London, United Kingdom (e-mail: Yongmin.Li@brunel.ac.uk). learning activities at school [5]. Self-efficacy is defined as individuals' beliefs in their own ability to complete desired actions or to appropriately perform in specific situations which in educational settings designate the conviction of being able to successfully cope with performance-related tasks, reach academic goal [6].

\section{BACKGROUND}

\section{A. Self-regulation and self-efficacy}

Self-regulation is defined as processes such as effortful control and orienting that function to modulate reactivity, while reactivity is responsiveness to change in the external and internal environment [7]. Many definitions had been given to the term self-regulation which is also called self-discipline and self-control. Self-regulation is a conscious effort to suppress overpowering responses to reach a higher goal [8]. It is therefore the ability carry on a task to completion even if boring and difficult, to listen to the teacher rather than daydreaming, the ability to organise work and plan actively, and choosing homework over computer games and TV [8]. This is also the degree to which learners are motivationally, behaviourally and metacognitive regulating their learning process [9].

Self-regulated learners use three significant features: different self-regulated strategies (active learning process that involve agency and purpose); have confidence in preforming efficaciously; and set many and wide-range of targets for themselves [10]. Researches had shown that learners with a high sense of academic efficacy display greater persistence, effort, and intrinsic interest in their academic learning and achievement [11]. Self-regulated learners also take part in three important process namely, self-observation (monitoring one's activities); self-judgement (evaluation of self-achievement compared with others or to a standard); and self-reactions (reactions to performance results)

Thus, self-regulated students set challenging targets for themselves by directing their learning process and achievements, through relevant approaches and by enlisting self-regulative impacts that encourage and direct their ability. Self-efficacy is defined as individuals' confidence in their ability to organise and execute a given course of action to solve a problem or accomplish a task [5]. He proposed a social cognitive model of motivation. This model was based on human agency and perceptions of efficacy. The construct comprises of generality, strength and difficulty in the multidimensional model.

\section{B. Test Anxiety}


Emotionality is the individual's subjective awareness of the heightened autonomic arousal rather than the arousal itself [12]. Researches have shown that high emotionality is associated with declining performance only when the individual is also experiencing high levels of worry [13], [12] It was also revealed that high levels of emotionality negatively stimulus test performance only under circumstances where the individual also experienced high level of worry, signifying that worry is the primary performance predictor [14]. Therefore, high level self-confidence regarding test performance is attributed to high level of emotionality. However, test anxiety has been attributed to behavioural phenomenon because this can modify and reduce test anxiety when emotionality component is targeted. This implies that student experience test anxiety when there is rise in levels of physiological arousal.

Cognitive test anxiety consists of individuals' cognitive reactions to evaluate situations, or internal dialogue regarding evaluative situations, before, during and after assessing the tasks [15]. Individuals with high levels of test anxiety usually have issues on extreme worry over assessment; comparing others performance with themselves; low levels of confidence in performance; consequences of failures; unprepared for assessment and loss of self-esteem [13], [14]. Path analyses have also confirmed that cognitive test anxiety had the strongest connection with performance.

\section{Motivation}

Motivation is defined as a set of interrelated beliefs and emotions that influence and direct behaviour [16]. It was revealed that $59 \%$ of the high-achieving students reported frequently to achieve goals to behave responsibly and to achieve academically, while just $38 \%$ and $34 \%$ of average achievers and low-achieving students respectively reported the same levels of efforts to achieve their targets [16].

Motivation is a process where goal directed activities begin and then eventually are sustained. Achievement motivation is commonly focused on studied in educational setting. Achievement motivation is enacted when an individual strives to be competent [17]. A related construct is Brophy's "motivation to learn," which is describes as more than doing the bare minimum to meet the requirements, but deliberately engaging in academic tasks with the intent to acquire new knowledge or skills [18].

Early theorists suggested that achievement motivation is caused by instincts, traits, needs, or drives [19]. It was noted that distinctive characteristics of a person determines achievement motivation need or trait. It was believed that students who have more of the achievement trait or drive will be more motivated towards success. Students should adapt to their emotional and cognitive request and conflicts as well as social settings and environmental cues [20]. This implies that students need to adjust their cognitive, motivational and emotional learning process [21]-[24].

\section{Research Questions}

Many researches had been conducted investigating the effect of negative emotions on students' academic performances. Researchers have found out that student's negative emotions seem to cause problems to adjust to school procedures. They also found out that anxiety result in poor academic performance because of low cognitive self-control exhibited by such students [25]. Ref. [26] found out that students who have negative emotions about their work and learning receive lower GPA in the 9th Grade, and graduate to a lesser extent, compared to students who have less negative emotions about their school work and learning. The result shows that students with negative emotions about their work and learning have predictive power for possible failure in school.

It was also found out that performance and mastery achievement goals, with an avoidance valence, correlate negatively with task and achievement outcomes [6]. They stated further that achievement emotions also predict academic performance, as emotions with positive valence, such as hope, emotions correlate positively with academic performance while those with negative valence, such as anxiety correlate negatively with academic performance. Ref. [27] noted that achievement emotions influence motivation, effort and learning strategies during tasks preparation and engagement.

This research therefore seeks to find answer to the following research questions: There is no relationship between the components of motivational beliefs and test anxiety; Academic achievement is not significant to motivational beliefs and test anxiety; and finally test anxiety do not correlates with academic performance.

\section{Methods}

This research was carried out using the ethnography research method. Ethnography allows real-life situations to be view and thus can be discussed and understood [28]. Ethnography allowed researchers to take part in events, observing activities, taking notes and gathering unformed data to generate an interpretation of the circumstances being studied (perhaps in a school or university rather than a little-known culture [29]. A wide range of options such as, audio or video recording can be used to record events using ethnography in academic environment that can be useful to the pedagogic researchers. This is because recordings improve correctness, in that it is likely to have a record of what was said, but may increase the investigator's load, particularly if an expert typist is not available to write them down.

In ref. [30], a "Quick and Dirty" ethnography was used to collect emotional data in a cognition and emotion support e-learning research, but stated that there is a trade-off between the efficiency and completeness in the method.

\section{A. Participants}

Participants for this research were twenty-four 200L students of department of Computer Science, Federal College of Education (Special), Oyo, Nigeria. Participation was voluntary and the participants were asked to fill the consent form at the beginning of study and they all agreed to take part in the research. The sample comprises of 14 males representing $58.3 \%$ and 10 females, representing $41.7 \%$. Participants were selected randomly and their age ranges from $16-27$ with mean age at 23.5 . 


\section{B. Learning Environment}

Two topics in Computer Science were taught the students who participated in the study. The class sessions were recorded and a test conducted after each class session. The researcher and the students later played the video session of each class and analysed the emotions identified on the students. Questionnaire was also distributed after the video analysis to obtain more data and clarification.

\section{Experimental Procedures}

The main procedures in this research are listed below:

1) Consultations with students to give details of the research aims and procedure.

2) Distributing consent form to all of them to fill to seek their approval.

3) Teacher strategies the lesson plans with the research team.

4) Introduce the study guide to the students.

5) Teaching the lesson and video recording of the class session.

6) After the class sessions as ended, the teacher gives test to the students.

7) The teacher and students interact to review the video to recall any emotions recognised.

8) Questionnaires were later distributed to students to obtain additional information.

\section{Measures}

Items from the Motivated Strategies for Learning Questionnaire (MSLQ) were used to measure the emotions learners experienced. Motivational beliefs were measured through self-efficacy, self-regulation test anxiety, intrinsic value, and cognitive strategy use. Items were made specific to Computer Science.
A total of 42 question items were used to measure the self-efficacy, intrinsic value, test anxiety, self-regulation and cognitive strategy use by students for learning. Opinions were measured using a 5-point Likert scale rating of 1 for Strongly Disagreed and 5 for Strongly Agreed. Cronbach's Alpha: .754 was achieved; Cronbach's Alpha based on standardized items: .881 using standardized 42 items.

Three types of measures were used for evaluating the class session: (a) Motivated Strategies for Learning Questionnaire (MSLQ), (b) interview after class session, and (c) grade of test. Learners' achievement was measure through the grade obtained in the test administered after the class session.

Self-efficacy was measured by nine (9) question items from the Motivational Strategies for Learning Questionnaire

(MSLQ). Students' responses were measured using a 5-point

Likert scale rating of 1 for strongly disagree and 5 for

Strongly Agree.

Intrinsic Value was measured using nine (9) question items from the MSLQ based on a Likert scale rating of 1 for strongly disagree and 5 for Strongly Agree.

Test anxiety was measured by four (4) question items from the MSLQ. Learners' opinions were measured on a Likert scale rating of 1 for strongly disagree and 5 for Strongly Agree.

Seven (8) question items form the MSLQ were used to measure students Self-Regulation. This was based on a Likert scale rating of 1 for strongly disagree and 5 for Strongly Agree.

Cognitive Strategy use was measured with twelve (12) question items from the MSLQ for obtain students responses. It was based on a Likert scale rating of 1 for strongly disagree and 5 for Strongly Agree.

TABLE I: DESCRIPTIVE ANALYSIS

\begin{tabular}{|l|l|l|l|l|l|}
\hline Strategies & Mean & Std. Deviation & \multirow{2}{*}{ Std. Error } & \multicolumn{2}{|l|}{$\mathbf{9 5 \%}$ conf. Interval for Mean } \\
\cline { 3 - 6 } & & & & Lower & Upper \\
\hline Self-Efficacy & 4.29 & 1.210 & .247 & 3.48 & 4.51 \\
\hline Intrinsic value & 3.70 & 1.195 & .244 & 2.20 & 3.21 \\
\hline $\begin{array}{l}\text { Cognitive } \\
\text { strategy use }\end{array}$ & 4.00 & 1.153 & .236 & 2.56 & 3.53 \\
\hline Self-Regulation & 3.99 & 1.175 & .240 & 3.50 & 4.49 \\
\hline Test Anxiety & 2.63 & 1.296 & .265 & 2.08 & 3.15 \\
\hline
\end{tabular}

TABLE II: CORRELATION

\begin{tabular}{|l|l|l|l|l|l|}
\hline Strategies & $\begin{array}{l}\text { Self-Effi } \\
\text { cacy }\end{array}$ & $\begin{array}{l}\text { Intrinsic } \\
\text { value }\end{array}$ & $\begin{array}{l}\text { Test } \\
\text { anxiety }\end{array}$ & $\begin{array}{l}\text { Cognitive } \\
\text { strategy use }\end{array}$ & Self-Regulation \\
\hline Self-Efficacy & - & $.50^{* *}$ & $-.48^{*}$ & $.83^{* *}$ & $.78^{* *}$ \\
\hline Intrinsic value & - & - & $.49^{* *}$ & $.69^{* *}$ & $.50^{*}$ \\
\hline Test anxiety & - & - & - & $.54 * *$ & $.39^{*}$ \\
\hline $\begin{array}{l}\text { Cognitive strategy } \\
\text { use }\end{array}$ & - & - & - & - & $.81^{* *}$ \\
\hline Self-Regulation & - & - & - & - & - \\
\hline
\end{tabular}

\section{MEASURES AND ANALYSIS ACHIEVEMENT}

\section{A. Results}

IBM SPSS statistics 20 was used to do the analysis for this study using many statistical tests. Some of the tests run were ANOVA, descriptive statistics, regression, reliability and correlations tests. Pearson's two-tailed correlations were used to find out the directional relationship within setting for each of the motivational beliefs and test anxiety. Descriptive 
analysis was also performed on the items of the questionnaire. There was high mean intensity in the motivational beliefs of Self-Efficacy with $M=4.29$ and Cognitive Strategy use with $M=4.00$. Test anxiety and intrinsic value however recorded low intensity with $M=2.63$ and 3.75 respectively as shown in Table I.

Correlation of the bivariate was conducted to obtain the Pearson's two-tailed test of significance. Self-efficacy was found to be highly correlated to cognitive strategy use at .83 and self-regulation at .78 as shown in Table II. Cognitive strategy use was also highly correlated to self-regulation at .81 , while intrinsic value correlation with cognitive strategy use was high at .69 and with self-regulation at .50 . This suggest that students who have self-efficacy and self-regulation use cognitive strategy, and students' high in self-efficacy were more likely to report use of cognitive strategy use and self-regulation. However, test anxiety recorded the lowest correlation with self-regulation at .39, negatively correlated to self-efficacy at -.48 and correlated with intrinsic value at .49 . This revealed that students low in self-regulation were more likely to report test anxiety. Furthermore, it was revealed that test anxiety is correlated to cognitive strategy use at .54 which implies that students' that reported medium level of cognitive strategy use are likely to have test anxiety.

TABLE III: REGRESSION COEFFICIENTS

TABLE III: REGRESSION COEFFICIENTS
\begin{tabular}{|l|l|l|l|l|c|}
\hline TestlAnxiety & B & SE B & B & t & Sig. \\
\hline Test1 & 3.622 & 3.105 & .330 & 1.167 & .694 \\
\hline Test 2 & 5.861 & 2.744 & .577 & 2.136 & .625 \\
\hline
\end{tabular}

To test for the relationship between test anxiety and academic performance, regression analysis was performed on test results and test anxiety, the result of the analyses of variance revealed as revealed in Table III shows that test anxiety is significantly correlated with test results with Test 1 at .694 and Test 2 at .625 .

Furthermore, one-way ANOVA was also performed to find out whether there is relationship between motivation beliefs and test anxiety. Levene's test measured by intrinsic value and self-regulation question items revealed a $\mathrm{F}(1,23)=$ 26.457, $\mathrm{p}=.852$; and self-regulation at $\mathrm{F}(1,23)=15.897, \mathrm{p}$ $=.602$. Test anxiety was also high at $\mathrm{F}(1,23)=12.193$, $\mathrm{p}$ $=.660$, as shown in Table IV.

TABLE IV: ANOVA

\begin{tabular}{|l|l|l|l|l|l|}
\hline \multicolumn{1}{|c|}{ Strategies } & $\begin{array}{l}\text { Sum } \\
\text { of } \\
\text { square }\end{array}$ & df & $\begin{array}{l}\text { Mean } \\
\text { square }\end{array}$ & F & Sig. \\
\hline Self-Efficacy & 28.114 & 1 & 1.219 & .954 & .339 \\
\hline Intrinsic value & 26.457 & 1 & 1.203 & .036 & .852 \\
\hline $\begin{array}{l}\text { Cognitive strategy } \\
\text { use }\end{array}$ & 12.883 & 1 & 1.357 & 0.764 & .563 \\
\hline Self-Regulation & 15.897 & 1 & 1.402 & 1.213 & .602 \\
\hline Test anxiety & 12.193 & 1 & 1.739 & 0.329 & .660 \\
\hline
\end{tabular}

\section{CONCLUSION}

The purpose of this study was to investigate the relationship between the components of the motivational beliefs namely, self-efficacy, intrinsic value, cognitive strategy use and self-regulation and test anxiety; and relationship between test anxiety and academic performances. Results from the research revealed that motivational beliefs are not correlated to test anxiety. Self-efficacy was highly correlated with cognitive strategy use and self-regulation indicated that students who report high in self-regulation also applied cognitive strategy and self-efficacy in achieving their goals. This shows that such students have self-control and self-discipline and are using efforts to overpower intense responses to reach their set targets.

The results also revealed that students that report high in self-regulation are more likely to report high in cognitive strategy use. The result of the study also revealed that there is high correlation between test anxiety and academic outcomes. This shows that students who have high test anxiety are likely to performance poorly in their examinations. This revealed that students low in self-regulation were more likely to report test anxiety.

\section{REFERENCES}

[1] R. Pekrun and E. J. Stephens, "Academic emotions," APA Educational Psychology Handbook Washington, DC: American Psychological Association Individual Differences and Cultural and Contextual Factors, vol. 2, pp. 3-31, 2012.

[2] P. A. Lowe, S. W. Lee, K. M. Witteborg, K. W. Prichard, M. E. Luhr, C. M Cullinan et al., "The test anxiety inventory for children and adolescents (TAICA)," Journal of Psychoeducational Assessment, vol. 26, pp. 215-230, 2008.

[3] M. Zeidner, Test Anxiety: The State of the Art, New York, NY: Plenum Press, 1998.

[4] M. Zeidner, "Test anxiety in educational contexts: Concepts, findings, and future directions," Emotion in Education, San Diego, CA: Academic Press, pp. 165-184, 2007.

[5] A. Bandura, "Self-efficacy. The exercise of control," Academic Performance of Adolescents. Psychological Science, vol. 16, no. 12, pp. 939-944, 1997.

[6] D. Putwain, P. Sander, and D. Larkin, "Academic self-efficacy in study-related skills and behaviours: Relations with learning-related emotions and academic success," The British Journal of Educational Psychology, vol. 83, pp. 633-650, 2013.

[7] M. K. Rothbart and J. E. Bates, "Temperament. Handbook of Child Psychology (6thed.)," Social, Emotional, and Personality Development, Hoboken, NJ: John Wiley \& Sons, Inc, vol. 3, pp. 99-166, 2006.

[8] A. L. Duckworth and E. P. Seligman, Self-discipline Outdoes IQ in Predicting, 2005.

[9] B. J. Zimmerman, "Self-regulating learning and academic achievement: An overview," Educational Psychologist, vol. 25, pp. 3-17, 1990.

[10] B. J. Zimmerman, "Attaining self-regulation: A social-cognitive perspective," pp. 13-39, 2000.

[11] D. H. Schunk, "Social cognitive theory and self-regulated learning," Self-regulated Learning and Academic Achievement: Theory, Research, and Practice, New York: Springer Verlag, Educational Psychologist, vol. 25, pp. 71-86, 1989.

[12] R. Schwarzer, "Worry and emotionality as separate components in test anxiety," Applied Psychology, vol. 33, no. 2, pp. 205-220, 1984.

[13] L. W. Morris, M. A. Davis, and C. H. Hutchings, "Cognitive and emotional components of anxiety: Literature review and a revised worry-emotionality scale," Journal of Educational Psychology, vol. 73, no. 4, p. 541, 1981.

[14] J. L. Deffenbacher, "Worry and emotionality in test anxiety," Test Anxiety: Theory, Research, and Applications, pp. 111-128, 1980.

[15] J. C. Cassady and R. E. Johnson, "Cognitive test anxiety and academic performance," Contemporary Educational Psychology, vol. 27, no. 2, pp. 270-295, 2002.

[16] K. R. Wentzel, "Social-motivational processes and interpersonal relationships: Implications for understanding motivation at school," Journal of Educational Psychology, vol. 91, pp. 76-97, 1999.

[17] A. J. Elliot and M. A. Church, "A hierarchical model of approach and avoidance achievement motivation," Journal of Personality and Social Psychology, vol. 72, no. 1, p. 218, 1997.

[18] G. Denzine and R. Brown, "Motivation to learn and achievement," Media Rich Instruction, Springer, Cham, June 2015. 
[19] D. H. Schunk, P. R. Pintrich, and J. L. Meece, "Motivation in education: Theory, research and application," Upper Saddle River, NJ: Merrill, 2008.

[20] S. Volet and S. Järvelä, "Motivation in learning contexts: Conceptual advances and methodological implications," Amsterdam, Elsevier, 2001.

[21] M. Boekaerts, "Self-regulated learning at the junction of cognition and motivation," European Psychologist, vol. 1, no. 2, pp. 100-112, 1996.

[22] M. Boekaerts, P. R. Pintrich, and M. Zeidner, Handbook of Self-regulation, Elsevier, 2005.

[23] P. H. Winne, "Self-regulated learning viewed from models of information processing," Self-regulated Learning and Academic Achievement: Theoretical Perspectives, vol. 2, pp. 153-189, 2001.

[24] B. J. Zimmerman, M. Boekarts, P. Pintrich, and M. Zeidner, "A social cognitive perspective," Handbook of Self-regulation, vol. 13, no. 1, pp. 695-716, 2000

[25] S. Normandeau and F. Guay, "Pre-school behaviour and first-grade school Achievement: The mediational role of cognitive self-control," Journal of Educational Psychology, vol. 90, pp. 111-121, 1998.

[26] A. Klapp, "The importance of self-regulation and negative emotions for predicting educational outcomes - Evidencefrom13-year olds in Swedish compulsory and upper secondary school," Learning and Individual Differences, vol. 52, pp 29-38, 2016.

[27] R. Pekrun, T. Goetz, R. P. Perry, K. Kramer, M. Hochstadt, and S. Molfenter, "Beyond test anxiety: Development and validation of the test emotions questionnaire (TEQ)," Anxiety, Stress and Coping, vol. 17, no. 3, 2004.

[28] B. Smit and E. Fritz, "Understanding teacher identity from a symbolic interactionist perspective: Two ethnographic narratives," South African Journal of Education, vol. 28, pp. 91-101, 2008.
[29] D. R. Cotton, A. Stokes, and P. A. Cotton, "Using observational methods to research the student experience," Journal of Geography in Higher Education, vol. 34, no. 3, pp. 463-473, 2010.

[30] X. Tao, Q. Niu, and M. Jackson, "Using an ethnographic approach to collect emotional data in affective learning research," International Journal of Information and Electronics Engineering, vol. 3, no. 2, p. 216, 2013.

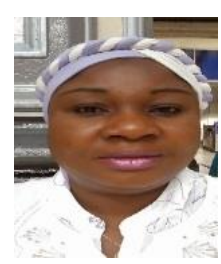

Shakirat Abimbola Adesola is a research student at the Department of Computer Science, Brunel University London, United Kingdom. She had her B.Sc. and M.Sc. from University of Ibadan, Nigeria. Her research area is on speech recognition and gender classification. She is on study leave from Federal College of Education (Special), Oyo, Nigeria.

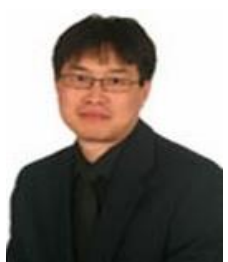

Yongmin $\mathbf{L i}$ is a senior lecturer with the Department of Computer Science, Brunel University London, United Kingdom. He received his PhD from Queen Mary, University of London, MEng and BEng from Tsinghua University, China. He is a senior member of the IEEE and also a fellow of the Higher Education Academy. He had worked with the British Telecom Laboratories before joining Brunel University London. He had published many articles in high profile journals. His research area is in image processing. 